\title{
Prediction and Quantification of Hepatic Transporter-Mediated Uptake of Pitavastatin Utilizing a Combination of the Relative Activity Factor Approach and Mechanistic Modeling ${ }^{\text {『 }}$
}

\author{
Pallabi Mitra, Samantha Weinheimer, Meeghan Michalewicz, and Mitchell E. Taub \\ Drug Metabolism and Pharmacokinetics Department, Boehringer Ingelheim Pharmaceuticals Inc., Ridgefield, Connecticut
}

Received January 22, 2018; accepted April 12, 2018

\begin{abstract}
Quantification of the fraction transported $\left(\mathrm{f}_{\mathrm{t}}\right)$ by a particular transporter will facilitate more robust estimations of transporter interactions. Using pitavastatin as a model uptake transporter substrate, we investigated the utility of the relative activity factor (RAF) approach and mechanistic modeling to estimate $f_{t}$ in hepatocytes. The transporters evaluated were organic anion-transporting polypeptides OATP1B1 and OATP1B3 and sodium-taurocholate cotransporting polypeptide. Transporter-expressing human embryonic kidney 293 cells and human hepatocytes were used for determining RAF values, which were then incorporated into the mechanistic model to simulate hepatocyte uptake of pitavastatin over time. There was excellent agreement between simulated and observed hepatocyte uptake of pitavastatin, indicating the suitability of this approach for translation of uptake from individual transporter-expressing cells to more holistic in vitro models.
\end{abstract}

\section{Introduction}

For a new chemical entity (NCE), in vitro evaluation as a potential substrate and inhibitor of key drug transporters aids in estimating the likelihood of drug-drug interactions (DDIs). If the NCE is a substrate of one or more of these key transporters in vitro, then a clinical trial involving concomitant administration with a selective inhibitor may be required. Results of such a study can then be extrapolated to estimate the DDI potential for other concomitantly administered drugs that interact with the same clearance pathway. However, this can be a resourcedemanding path forward for a compound in clinical development and may not be the most efficient way to ensure patient safety. As such, a bridge between these two steps [i.e., establishing a more mechanistically derived in vitro-in vivo correlation (IVIVC)] could in principle provide improved estimation of the extent to which the disposition of the NCE would be affected by inhibition of a particular transporter. Such analyses can then guide clinical teams more confidently regarding the need for a clinical DDI study.

This work was supported by Boehringer Ingelheim Pharmaceuticals Inc. https://doi.org/10.1124/dmd.118.080614.

S This article has supplemental material available at dmd.aspetjournals.org.
Subsequently, $f_{t}$ values were determined. The largest contributor to hepatocyte uptake of pitavastatin was OATP1B1, which correlates with what is known about the in vivo disposition of pitavastatin. The $f_{t}$ values were then used for evaluating in vitro-in vivo correlations of hepatic uptake inhibition with OATP inhibitors rifampicin and cyclosporine. Predictions were compared with previously reported plasma exposure changes of pitavastatin with these inhibitors. Although hepatic uptake inhibition of pitavastatin was 2-3-fold underpredicted, incorporation of scaling factors (SFs) into RAF values significantly improved the predictive ability. We propose that calibration of hepatocytes with standard transporter substrates and inhibitors would allow for determination of system-specific SFs, which could subsequently be used for refining predictions of clinical DDI potential for new chemical entities that undergo active hepatic uptake.

ABBREVIATIONS: AAFE, absolute average fold error; AFE, average fold error; AUC, area under the plasma concentration-time curve; AUCR, ratio of area under the curve values obtained in the presence and absence of an inhibitor; CCK-8, cholecystokinin octapeptide; CL, clearance; DDI, drugdrug interaction; DRF, dynamic relative activity factor approach; E3S, estrone-3-sulfate; HEK293, human embryonic kidney 293; IVIVC, in vitro-in vivo correlation; MRP3, multidrug resistance-associated protein 3; NCE, new chemical entity; NTCP, sodium-taurocholate cotransporting polypeptide; OATP, organic anion-transporting polypeptide; PBPK, physiologically based pharmacokinetic modeling; PK, pharmacokinetic; RAF, relative activity factor; REF, relative expression factor; $\mathrm{SCHH}$, sandwich-cultured human hepatocyte; SF, scaling factor; TCA, taurocholic acid. 
value was estimated by expressing $\mathrm{CL}_{\mathrm{i}}$ as a fraction of total predicted hepatocyte uptake clearance. While useful, this static approach lacked the integration of multiple processes occurring simultaneously over time. Recently however, the scope of the REF approach was expanded to integrate other processes (passive diffusion and efflux transport) and for predicting hepatocyte uptake over time as a function of all of these processes (Vildhede et al., 2016). This more dynamic method provided substantial improvement in identification of transporters that were most critical to hepatocyte uptake and elimination of pitavastatin. A dynamic approach was also recently employed to estimate RAF and renal clearance from data obtained in individually transfected human embryonic kidney 293 (HEK293) cells; however, the lack of a holistic in vitro model for the kidney limits the translation of data from individually transfected HEK293 cells to such a holistic model (Mathialagan et al., 2017). To date, the RAF approach has not been employed for dynamic predictions of cellular uptake of a compound that is a substrate of multiple hepatic uptake transporters, nor has it been used for estimating $\mathrm{f}_{\mathrm{t}}$, via extrapolation from transfected cells to hepatocytes. The primary advantage of such a dynamic approach is the ability to integrate multiple processes (passive diffusion, uptake, efflux, and metabolism) and thus, in principle, provide a more integrated value for $\mathrm{f}_{t}$ compared with static methods.

In this study, a similar dynamic approach, as used by Vildhede et al. (2016), has been used to estimate $f_{t}$ of hepatocyte uptake of pitavastatin. However, RAF, not REF, was used as the quantitation method. In this approach, henceforth referred to as the dynamic relative activity factor approach (DRF), uptake of pitavastatin into hepatocytes was predicted by integrating multiple uptake transporter clearances, bidirectional passive diffusion, and basolateral efflux clearance. Pitavastatin was chosen as the test compound, since the predominant hepatic elimination pathway of pitavastatin is active uptake (Watanabe et al., 2010; Jigorel and Houston, 2012; Riede et al., 2016). After prediction of hepatocyte uptake, $f_{t}$ values were estimated and subsequently employed for estimating the IVIVC of hepatic uptake inhibition, as a means of predicting clinical outcomes.

\section{Materials and Methods}

\section{Chemicals and Reagents}

$\left[{ }^{3} \mathrm{H}\right]$-estrone-3-sulfate (E3S; $\left.50 \mathrm{Ci} / \mathrm{mmol}\right)$ and $\left[{ }^{3} \mathrm{H}\right]$-pitavastatin $(5 \mathrm{Ci} / \mathrm{mmol})$ were purchased from American Radiolabeled Chemicals (St. Louis, MO). $\left[{ }^{3} \mathrm{H}\right]-$ cholecystokinin octapeptide (CCK-8; $98.7 \mathrm{Ci} / \mathrm{mmol})$ and $\left[{ }^{3} \mathrm{H}\right]$-taurocholic acid (TCA; $10 \mathrm{Ci} / \mathrm{mmol}$ ) were purchased from Perkin Elmer (Shelton, CT). Pitavastatin calcium was purchased from Santa Cruz Biotechnology (Dallas, TX), CCK-8 was obtained from Phoenix Pharmaceuticals Inc. (Burlingame, CA), whereas E3S sodium salt and TCA sodium salt were purchased from SigmaAldrich (Burlington, MA). Cryopreserved human hepatocyte lots HUM4122D and HUP1001 were purchased from Lonza (Walkersville, IL), whereas lots Hu1651 were purchased from Life Technologies (Carlsbad, CA). Donor characteristics are provided in Supplemental Table 1.

\section{In Vitro Transport Studies}

Organic Anion-Transporting Polypeptide and Sodium-Taurocholate Cotransporting Polypeptide Substrate Assays in HEK293 Cells. HEK293 cells were maintained and transiently transfected with human organic aniontransporting polypeptide OATP1B1, OATP1B3, sodium-taurocholate cotransporting polypeptide (NTCP), or vector-control cDNA as per previously published procedures (Taub et al., 2011). All uptake assays were conducted at $37^{\circ} \mathrm{C}$. Total uptake was determined from uptake in transporter-transfected cells, whereas passive uptake was determined from uptake in vector-transfected cells. The linear range of time-dependent uptake was assessed from initial experiments (data not shown). Subsequently, the incubation time of each substrate selected for concentration-dependent uptake assays was as follows: 1 minute for E3S and pitavastatin and 3 minutes for TCA and CCK-8. Uptake assays were initiated by adding either radiolabeled compound or a mixture of radiolabeled compound and nonradiolabeled compound to each well. Assays were conducted and samples were lysed as published previously (Taub et al., 2011). Cellular uptake was quantified by liquid scintillation counting. The total cellular protein content was determined by the Bradford method (Stoscheck, 1990).

Hepatocyte Selection. Donor characteristics and uptake characteristics of hepatocyte lots are provided in Supplemental Table 1. Hepatocyte lots were selected based on vendor certification of uptake activity and further qualified in house with respect to active uptake of E3S. Hepatocyte lots that exhibited significant active uptake of E3S were used for this study.

OATP and NTCP Substrate Assays in Hepatocytes in Suspensions. The oil-spin centrifugation method was used to assess uptake in hepatocyte suspensions and was based on protocol of Bioreclamation IVT (Westbury, NY). Because this protocol can no longer be accessed on the supplier's website, details of the assay are provided in the Supplemental Material (section 2). For all compounds, total uptake was evaluated at $37^{\circ} \mathrm{C}$, and passive uptake was evaluated at $4^{\circ} \mathrm{C}$. For E3S, passive uptake was also evaluated at $37^{\circ} \mathrm{C}$ in the presence of $100 \mu \mathrm{M}$ rifamycin $\mathrm{SV}$, an inhibitor of OATP1B1 and OATP1B3. Initial experiments were conducted to determine the linear range of time-dependent uptake. Subsequently, the incubation times selected for concentration-dependent uptake assays were as follows: 1 minute for E3S and pitavastatin and 3 minutes for TCA and CCK-8. Substrate solutions were prepared in Krebs-Henseleit buffer for all assays except when passive diffusion was assessed by NTCP, in which sodiumfree buffer was prepared as described previously (Taub et al., 2011). Uptake assays were conducted with either only radiolabeled compound or a mixture of radiolabeled compound and nonradiolabeled compound. The only change made to the supplier's protocol was that after centrifugation through the oil layer, each tube was placed on dry ice for at least 20 minutes. The tubes were then cut, and the bottom layer of each tube containing the cell pellet was lysed in 1\% SDS solution. Samples were quantified by liquid scintillation counting, and total cellular protein content was determined by the Bradford method (Stoscheck, 1990).

OATP and NTCP Substrate Assays in Sandwich-Cultured Human Hepatocytes. Single donor primary human hepatocytes were cultured according to the supplier's protocols (https://www.lonza.com/products-services/bio-research/adme-tox/hepatocytes-and-media.aspx). Further details of the assay are provided in the Supplemental Material (section 2). At approximately 24 hours after plating, cells were overlaid with Matrigel. Uptake assays were conducted 5 days after the addition of Matrigel to allow formation of bile canaliculi (Vildhede et al., 2016). For all compounds, total uptake was assessed at $37^{\circ} \mathrm{C}$, whereas passive uptake was evaluated at $4^{\circ} \mathrm{C}$. Passive uptake of E3S was also evaluated at $37^{\circ} \mathrm{C}$ in the presence of $100 \mu \mathrm{M}$ rifamycin SV. Initial experiments were conducted to determine the linearity of time-dependent uptake. Subsequently, the incubation times selected for concentration-dependent uptake assays were as follows: 1 minute for E3S and pitavastatin and 3 minutes for TCA and CCK-8. The uptake buffer was Krebs-Henseleit buffer for all assays except when passive diffusion was assessed by NTCP, in which sodium-free buffer was prepared as described previously (Taub et al., 2011). For initiation of uptake studies, substrate solutions containing either radiolabeled compound or a mixture of radiolabeled compound and nonradiolabeled compound were added to each well. At the end of the incubation, the incubation buffer was collected. The cells were washed with ice-cold buffer and lysed in $1 \%$ SDS. The incubation buffers (before and after incubation) and the cellular lysates were quantified by liquid scintillation counting to determine amounts of compound in the incubation medium and cells, respectively. Total cellular protein content was determined by the Bradford method. To determine the amount of protein associated with cells, protein concentrations of control wells containing Matrigel only were subtracted from total protein concentrations determined from wells containing cells and Matrigel.

\section{Determination of Kinetic Constants of Active Uptake and RAF Values}

In all of the transport assays above, active uptake was determined by subtracting passive uptake from total uptake. The active uptake of each substrate was subsequently subjected to Eadie-Hofstee transformations. In situations in which biphasic uptake profiles were observed in the Eadie-Hofstee plots, only the high-affinity component of uptake (saturable component) was considered for estimating kinetic constants $\left(K_{\mathrm{m}}\right.$ and $\left.V_{\max }\right)$ using the Michaelis-Menten equation 
as shown below in eq. 1. GraphPad Prism (version 6; GraphPad Software Inc., La Jolla, CA) was used for the analyses.

$$
V=\frac{V_{\max } \cdot[\mathrm{S}]}{K_{\mathrm{m}}+[\mathrm{S}]}
$$

where $V$ is the active uptake rate (in picomoles per minute per milligram protein), $V_{\max }$ is the predicted maximal active uptake rate, [S] is the substrate concentration (in micromoles), and $K_{\mathrm{m}}$ is the substrate concentration at which $V_{\max }$ is half of the maximum value.

Uptake clearances $\left(\mathrm{CL}_{\mathrm{int}}\right.$; in microliters per minute per milligram protein) for each substrate were subsequently estimated as shown in eq. 2 .

$$
\mathrm{CL}_{\mathrm{int}}=\frac{V_{\max }}{K_{\mathrm{m}}}
$$

The RAF is defined as the ratio of clearance in human hepatocytes to clearance in transfected cells (Chapy et al., 2015) and was calculated from eq. 3.

$$
\mathrm{RAF}=\frac{\mathrm{CL}_{\text {int, hepatocytes }}}{\mathrm{CL} \text { int, HEK }}
$$

RAF values for OATP1B1, OATP1B3, and NTCP were calculated from the uptake kinetics of E3S, CCK-8, and TCA, respectively. It is well known that CCK-8 and TCA are selective substrates of OATP1B3 and NTCP, and this was true in initial experiments. E3S has previously been used as a selective OATP1B1 substrate for RAF purposes (Hirano et al., 2004; Kunze et al., 2014). E3S is a substrate of NTCP as well and a small portion of the uptake of E3S in hepatocytes is facilitated by NTCP; this was further corrected as follows: the uptake clearance of E3S in HEK-NTCP was multiplied by the hepatocyte RAF-NTCP values to obtain an estimate of the NTCP-mediated clearance of E3S in hepatocytes. The estimated NTCP-mediated E3S clearance in hepatocytes was subsequently subtracted from the observed E3S active uptake clearance in hepatocytes. The resulting E3S uptake clearance in hepatocytes was considered to reflect OATP1B1-mediated uptake clearance in hepatocytes and was used to determine the RAF of OATP1B1.

\section{Mechanistic Model of In Vitro Hepatocyte Disposition of Pitavastatin}

A two-compartment model was constructed in Phoenix WinNonlin (version 6.3; Certara, Princeton, NJ) to represent the hepatocyte uptake process (eqs. 4 and 5 ), with the two compartments representing the media and the cells.

$$
\begin{aligned}
\frac{\mathrm{dA}_{\mathrm{med}}}{\mathrm{dt}}= & -\left(\mathrm{CL}_{\mathrm{passive}}+\mathrm{CL}_{\mathrm{OATP1B} 1}+\mathrm{CL}_{\mathrm{OATP} 1 \mathrm{~B} 3}+\mathrm{CL}_{\mathrm{NTCP}}\right) *\left(C_{\mathrm{med}} * \mathrm{f}_{\mathrm{u}, \mathrm{med}}\right) \\
& -\left(\mathrm{NSB} *\left(\mathrm{C}_{\mathrm{med}} * \mathrm{f}_{\mathrm{u}, \mathrm{med}}\right)\right)+\left(\mathrm{CL}_{\text {passive }}+\mathrm{CL}_{\mathrm{MRP} 3}+\mathrm{CL}_{\mathrm{BCRP}}+\mathrm{CL}_{\mathrm{P}-\mathrm{gp}}\right) \\
& *\left(C_{\text {cell }} * \mathrm{f}_{\mathrm{u}, \text { cell }}\right)
\end{aligned}
$$

$$
\begin{aligned}
\frac{\mathrm{dA}_{\text {cell }}}{\mathrm{dt}}= & +\left(\mathrm{CL}_{\text {passive }}+\mathrm{CL}_{\mathrm{OATP} 1 \mathrm{~B} 1}+\mathrm{CL}_{\mathrm{OATP1B} 3}+\mathrm{CL}_{\mathrm{NTCP}}\right) *\left(\mathrm{C}_{\mathrm{med}} * \mathrm{f}_{\mathrm{u}, \text { med }}\right) \\
& -\left(\mathrm{CL}_{\text {passive }}+\mathrm{CL}_{\mathrm{MRP} 3}+\mathrm{CL}_{\mathrm{BCRP}}+\mathrm{CL}_{\mathrm{P} \text {-gp }}\right) *\left(\mathrm{C}_{\text {cell }} * \mathrm{f}_{\mathrm{u}, \text { cell }}\right)
\end{aligned}
$$

where $\mathrm{A}_{\text {med or cell }}$ is the amount of substrate in medium or cell at time $t$ and $C_{\text {med or }}$ cell is the total concentration of compound in the medium or cells at time $t . \mathrm{V}_{\text {med or }}$ cell (volume of media or cells) was used to estimate $C_{\text {med or cell }}$, and $\mathrm{V}_{\text {med }}$ was 500 and $150 \mu \mathrm{l}$ for hepatocytes in sandwich culture and suspension, respectively. $\mathrm{V}_{\text {cell }}$ was considered to be $3.9 \mu \mathrm{l} / \mathrm{million}$ cells for hepatocytes in suspension (Ménochet et al., 2012b) and $7.4 \mu \mathrm{l} / \mathrm{mg}$ total protein for sandwich-cultured human hepatocytes (SCHHs) (Pfeifer et al., 2013). $\mathrm{f}_{\mathrm{u} \text {,med }}$ is the fraction unbound in media (equal to 1) and $\mathrm{f}_{\mathrm{u}, \text { cell }}$ is the fraction unbound in cells. NSB (nonspecific binding) is the fraction of pitavastatin lost per minute due to nonspecific binding between the first and last sampling time points (units are in $\mathrm{min}^{-1}$ ).

$\mathrm{CL}$ refers to clearance mediated by either passive diffusion $\left(\mathrm{CL}_{\text {passive }}\right)$ or transporters. Equations 4 and 5 show all transporters that are known to affect the hepatocyte disposition of pitavastatin. However, in suspension hepatocytes, biliary networks are not known to form. In SCHHs, in this case, the experimental setup did not differentiate between accumulation between cells and between bile. Hence, in both situations, $\mathrm{CL}_{\mathrm{BCRP}}$ and $\mathrm{CL}_{\mathrm{P} \text {-gp }}$ were considered to be 0 . Thus, hepatocyte disposition of pitavastatin was modeled through eqs. 6 and 7 as shown below. Of note, the error codes associated with both $C_{\text {med }}$ and $C_{\text {cell }}$ were additive.

$$
\begin{aligned}
\frac{\mathrm{dA}_{\text {med }}}{\mathrm{dt}}= & -\left(\mathrm{CL}_{\text {passive }}+\mathrm{CL}_{\mathrm{OATP} 1 \mathrm{~B} 1}+\mathrm{CL}_{\mathrm{OATP} 1 \mathrm{~B} 3}+\mathrm{CL}_{\mathrm{NTCP}}\right) *\left(C_{\mathrm{med}} * \mathrm{f}_{\mathrm{u}, \text { med }}\right) \\
& -\left(\mathrm{NSB} *\left(\mathrm{C}_{\mathrm{med}} * \mathrm{f}_{\mathrm{u}, \text { med }}\right)\right)+\left(\mathrm{CL}_{\text {passive }}+\mathrm{CL}_{\mathrm{MRP} 3}\right) *\left(C_{\text {cell }} * \mathrm{f}_{\mathrm{u}, \text { cell }}\right) \\
\frac{\mathrm{dA}_{\text {cell }}}{\mathrm{dt}}= & +\left(\mathrm{CL}_{\text {passive }}+\mathrm{CL}_{\mathrm{OATP} 1 \mathrm{~B} 1}+\mathrm{CL}_{\mathrm{OATP} 1 \mathrm{~B} 3}+\mathrm{CL}_{\mathrm{NTCP}}\right) *\left(C_{\mathrm{med}} * \mathrm{f}_{\mathrm{u}, \mathrm{med}}\right) \\
& -\left(\mathrm{CL}_{\text {passive }}+\mathrm{CL}_{\mathrm{MRP} 3}\right) *\left(C_{\text {cell }} * \mathrm{f}_{\mathrm{u}, \text { cell }}\right)
\end{aligned}
$$

Transporter-mediated uptake clearance $\left(\mathrm{CL}_{\text {transporter }}\right)$ in eqs. 6 and 7 above was further delineated as shown in eq. 8 :

$$
\mathrm{CL}_{\text {uptake transporter }}=\frac{V_{\text {max }} \cdot \mathrm{RAF}}{K_{\mathrm{m}}+\left[C_{\mathrm{med}} * \mathrm{f}_{\mathrm{u}, \text { med }}\right]}
$$

where $V_{\max }$ and $K_{\mathrm{m}}$ are the uptake kinetic constants of pitavastatin determined in the HEK293 cells for a particular transporter, and RAF is the corresponding RAF of the transporter. The only efflux transporter pertinent to our experimental setup was multidrug resistance-associated protein 3 (MRP3). For MRP3, the efflux clearance parameters were obtained from the literature (Vildhede et al., 2016) and were not estimated in this experiment.

Due to nonspecific binding of pitavastatin (experimentally estimated to be $10 \%-20 \%$ ), the initial amount available to the cells was determined from either buffer incubations on plastic at 1 minute (the shortest time point) or from total radioactivity recovered in buffer and cells at 1 minute, whichever value was highest. Of note, it has been reported that the $\mathrm{f}_{\mathrm{u}, \mathrm{med}}$ of pitavastatin (obtained from fitting) can be as low as 0.63 (Ménochet et al., 2012b), which presumably is due to nonspecific binding of pitavastatin.

\section{Determination of Fraction Unbound in Cells and $\mathbf{C L}_{\text {passive }}$}

$\mathrm{CL}_{\text {passive }}$ and $\mathrm{f}_{\mathrm{u}, \text { cell }}$ were derived by fitting hepatocyte disposition of pitavastatin at $4^{\circ} \mathrm{C}$ to the two-compartment model (eqs. 6 and 7 above). All transporter-associated clearances were fixed to 0 (under the assumption that active processes are not functional at $4^{\circ} \mathrm{C}$ ). Loss of pitavastatin from media and uptake of pitavastatin into cells were simultaneously fit to obtain $\mathrm{CL}_{\text {passive }}$ and $\mathrm{f}_{\mathrm{u}, \text { cell }}$.

The $\mathrm{f}_{\mathrm{u}, \text { cell }}$ was also calculated by the method of Shitara et al. (2013). $K_{\mathrm{p}}$ is defined as the ratio of the total concentration of compound in cells to the total concentration in media at steady state. In this approach, the inverse of the $K_{\mathrm{p}}$ at $4^{\circ} \mathrm{C}$ is considered to be equal to the fraction unbound in cells. Henceforth, this method is referred to as the "steady-state method."

\section{Predictive Ability of the Two-Compartment Model}

The bias of the predictions and the scatter associated with the predictions were assessed from the average fold error (AFE), and absolute average fold error (AAFE), respectively, and are shown in eqs. 9 and 10.

$$
\begin{gathered}
\mathrm{AFE}=10^{\frac{1}{\mathrm{n}} \sum \log \frac{\text { Predicted }}{\text { Observed }}} \\
\mathrm{AAFE}=10^{\frac{1}{n} \sum \log \frac{\mid \text { Predicted }}{\mid \text { Observed } \mid}}
\end{gathered}
$$

\section{Determinations of $\mathbf{f}_{\mathbf{t}}$ by a Particular Transporter}

As mentioned previously, the hepatocyte model (eqs. 6 and 7) accounted for multiple hepatic disposition processes of pitavastatin. The hepatocyte accumulation of pitavastatin due to each individual process $\left(\mathrm{CL}_{\text {passive }}\right.$ or $\left.\mathrm{CL}_{\text {uptake transporter }}\right)$ was simulated, one at a time, and the area under the curve AUCin-vitro of each individual process was calculated by noncompartmental analysis. AUC values of the individual processes (passive diffusion, OATP1B1, OATP1B3, and NTCP) were added to obtain a total simulated AUC. Of note, total simulated AUC values were similar to observed AUC values. Subsequently, the AUC of each individual process was expressed as a fraction of the total simulated AUC to obtain the $\mathrm{f}_{\mathrm{t}}$. Initial simulations showed MRP3 to have minimal impact on hepatocyte disposition. Thus, MRP3 was not considered in the final $f_{t}$ calculations. 
TABLE 1

Kinetic parameters of active uptake of transporter substrates and pitavastatin in transfected HEK293 cells

Data are presented as means \pm S.D. unless indicated otherwise.

\begin{tabular}{llccc}
\hline \multicolumn{1}{c}{ Substrate } & \multicolumn{1}{c}{ Cell Type } & $K_{\mathrm{m}}$ & $V_{\max }$ & $V_{\max } / K_{\mathrm{m}}$ \\
\hline & & $\mu M$ & pmol/min per milligram & $\mu l /$ min per milligram \\
E3S & HEK293-OATP1B1 & $0.52 \pm 0.03$ & $45.4 \pm 0$ & 87.7 \\
CCK-8 & HEK293-OATP1B3 & $3.1 \pm 0.7$ & $55.1 \pm 16.5$ & 19.0 \\
TCA & HEK293-NTCP & 14.9 & 1191 & 79.9 \\
Pitavastatin & HEK293-OATP1B1 & $4.2 \pm 0.1$ & $187.2 \pm 32.5$ & $44.4 \pm 6.7$ \\
& HEK293-OATP1B3 & $2.2 \pm 0.1$ & $74.2 \pm 37.8$ & $32.6 \pm 14.8$ \\
& HEK293-NTCP & $24.3 \pm 3.1$ & $866 \pm 283$ & $35.2 \pm 7.1$ \\
\hline
\end{tabular}

Each experiment was done twice except the TCA uptake experiment in HEK293-NTCP, which was done once.

\section{IVIVCs of Inhibition of Uptake of Pitavastatin}

IVIVCs of inhibition of uptake were determined from the Rowland-Matin equation (eq. 11), which is a method of estimating the fold change in exposure due to inhibition of a particular elimination pathway (in this case, transporters) by a particular inhibitor. This equation/approach has been employed previously for calculating AUC (area under the plasma concentration time curve) fold changes resulting from hepatic uptake inhibition (Elsby et al., 2012; Shen et al., 2013).

$$
\mathrm{AUCR}=\frac{\mathrm{AUC}_{\mathrm{i}}}{\mathrm{AUC}_{\mathrm{c}}}=\frac{1}{\sum_{i=1}^{n} \frac{f_{i} f_{h}}{1+[I] / K_{i}}+\left(1-\sum_{i=1}^{n} f_{t} f_{h}\right)}
$$

where AUCR is the ratio of area under the curve values obtained in the presence and absence of an inhibitor. AUCi and AUCc are the AUC in the presence or absence of an inhibitor, respectively. $\mathrm{f}_{\mathrm{t}}$ is the fraction transported, $K_{\mathrm{i}}$ is the reversible inhibition constant. $[I]$ is the in vivo concentration of the inhibitor, and for this parameter, unbound hepatic inlet concentration $\left([I]_{\mathrm{u}, \text { inlet,max }}\right)$ was considered. $K_{\mathrm{i}}$ values and physicochemical properties/pharmacokinetic (PK) parameters used for calculating $[I]_{\mathrm{u}, \text { inlet,max }}$ were obtained from the literature and are provided in Supplemental Table 3.

In eq. $9, \mathrm{f}_{\mathrm{h}}$ is the fraction of pitavastatin eliminated by the liver. The fraction of pitavastatin eliminated in urine as unchanged pitavastatin is 3\% (as provided on the Livalo label; Kowa Pharmaceuticals America Inc., Montgomery, AL; https:// www.accessdata.fda.gov/scripts/cder/daf/index.cfm?event=overview.process $\& A p p l N o=022363)$. Thus, $f_{h}$ was estimated to be 0.97 . Of note, renal clearance of pitavastatin is often considered to be 0 (Varma et al., 2014; Riede et al., 2016); hence, the value of 0.97 is a reasonable estimation of $f_{h}$ of pitavastatin.

\section{Results}

\section{Uptake of E3S, CCK-8, TCA, and Pitavastatin in HEK293- Transfected Cells}

Concentration-dependent uptake of E3S, CCK-8, and TCA was evaluated in HEK293 cells transfected with OATP1B1, OATP1B3, and NTCP, respectively. Total, passive, and active uptake of each substrate is shown in Supplemental Fig. 1, and the kinetic constants of active uptake are listed in Table 1 . As shown in Table 1 , the $K_{\mathrm{m}}$ values of all three substrates were similar to what has been reported previously for the corresponding transporter $(\leq 1 \mu \mathrm{M}$ for high-affinity binding of E3S to OATP1B1, 3.8-6.5 $\mu \mathrm{M}$ for CCK-8, and 5.4-22.1 $\mu \mathrm{M}$ for TCA) (Hirano et al., 2004; Leonhardt et al., 2010; Schwarz et al., 2011; DeGorter et al., 2012; Sharma et al., 2012; De Bruyn et al., 2014; Gozalpour et al., 2014; Marada et al., 2015).

The concentration-dependent uptake of pitavastatin was also evaluated. Values describing the total, passive, and active uptake of pitavastatin are shown in Supplemental Fig. 1, and the kinetic constants of active uptake are listed in Table 1 . As shown in Table 1 , the $K_{\mathrm{m}}$ values of pitavastatin for OATP1B1, OATP1B3, and NTCP in this study were similar to previously reported values $(0.8-4.8 \mu \mathrm{M}$ for OATP1B1, 2.6-3.3 $\mu \mathrm{M}$ for OATP1B3, and $38.5 \mu \mathrm{M}$ for NTCP) (Hirano et al., 2004; Sharma et al., 2012; Soars et al., 2012; Izumi et al., 2015; Vildhede et al., 2016).

TABLE 2

Kinetic parameters of active uptake of transporter substrates in hepatocytes in suspension or sandwich culture (SCHHs)

Data are presented as means \pm S.D. unless indicated otherwise.

\begin{tabular}{|c|c|c|c|c|c|c|}
\hline Substrate & Hepatocyte Format & Hepatocyte Lot & $K_{\mathrm{m}}$ & $V_{\max }$ & $V_{\max } / K_{\mathrm{m}}$ & RAF \\
\hline & & & $\mu M$ & pmol/min per milligram & $\mu l / m i n$ per milligram & \\
\hline \multirow[t]{7}{*}{ E3S } & Suspension & HUP1001 & 1.14 & 77.63 & 67.9 & 0.68 \\
\hline & & HUP1001 (rifamycin SV) & 0.93 & 166.2 & 179.3 & 1.95 \\
\hline & & HUM122D & 0.53 & 114.8 & 218.2 & 2.43 \\
\hline & & HUM4122D (rifamycin SV) & $0.32 \pm 0.032$ & $84.4 \pm 6.5$ & $269 \pm 48$ & $3.02 \pm 0.55$ \\
\hline & $\mathrm{SCHH}$ & HU1651 & 0.7 & 84.8 & 121 & 1.16 \\
\hline & & HUM4122D & 1.25 & 141.8 & 113.1 & 1.18 \\
\hline & & HUM4122D (rifamycin SV) & 0.52 & 56 & 108 & 1.12 \\
\hline \multirow[t]{4}{*}{ CCK-8 } & Suspension & HUP1001 & $\mathrm{NC}^{a}$ & $\mathrm{NC}$ & $0.71^{b}$ & 0.04 \\
\hline & & HUM122D & 1.2 & 6.8 & 5.8 & 0.31 \\
\hline & $\mathrm{SCHH}$ & HU1651 & 1.9 & 3.0 & 1.6 & 0.09 \\
\hline & & HUM4122D & 1.3 & 7.6 & 5.9 & 0.31 \\
\hline \multirow[t]{4}{*}{ TCA } & Suspension & HUP1001 & 23.6 & 437 & 18.5 & 0.23 \\
\hline & & HUM122D & 21.4 & 246 & 11.5 & 0.14 \\
\hline & SCHH & HU1651 & 12.9 & 594.3 & 45.9 & 0.57 \\
\hline & & HUM4122D & 25.6 & 577.1 & 22.6 & 0.28 \\
\hline
\end{tabular}

Each experiment was done once except the HUM4122D rifamycin SV experiments, which were done twice. NC, not calculated.

${ }^{a}$ Not calculated due to low active uptake.

${ }^{b}$ Clearance averaged from concentrations where uptake at $37^{\circ} \mathrm{C}>$ uptake at $4{ }^{\circ} \mathrm{C}$. 

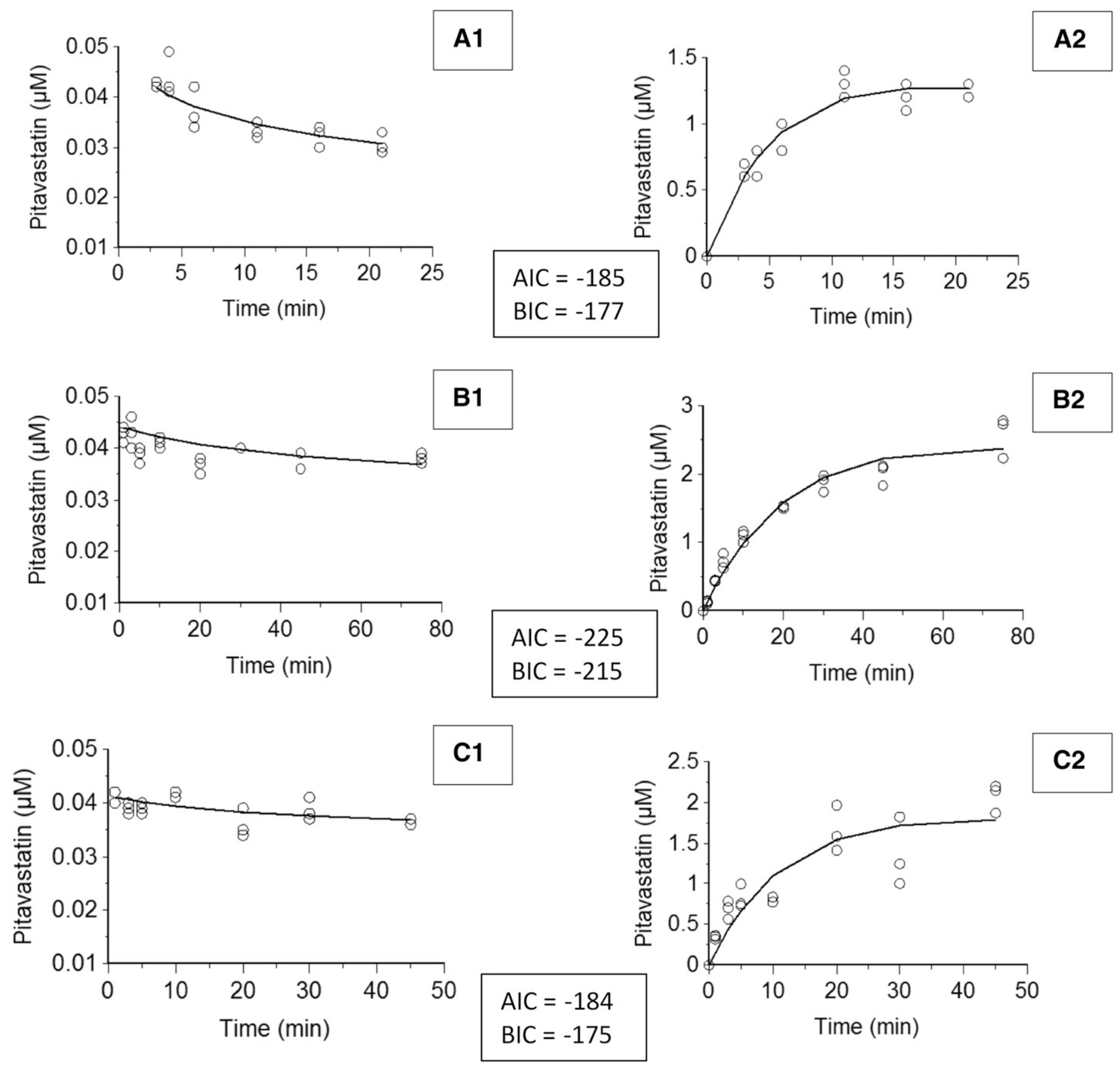

Fig. 1. Fitting of the time-dependent hepatocyte uptake of pitavastatin at $4^{\circ} \mathrm{C}$ as represented by media $(\mathrm{A} 1-\mathrm{C} 1)$ and intracellular (A2-C2) concentrations. Open circles represent observed data (individual values) and solid lines represent simulations. (A1 and A2) Suspension, lot HUM4122D. (B1 and B2) SCHH lot HUM4122D. (C1 and C2) SCHH lot HU1651. 'AIC' is Akaike Information Criteria and 'BIC' is Bayesian Information Criteria.'

\section{Uptake of E3S, CCK-8, and TCA in Hepatocytes and Estimation of RAF Values}

Concentration-dependent uptake of E3S, CCK-8, and TCA in suspension and sandwich-cultured hepatocytes was evaluated. For E3S, passive diffusion was estimated at $4{ }^{\circ} \mathrm{C}$ and also at $37^{\circ} \mathrm{C}$ in the presence of $100 \mu \mathrm{M}$ rifamycin SV. There was no appreciable difference in passive uptake of E3S between these two approaches. Hence, for CCK- 8 and TCA, incubations at $4{ }^{\circ} \mathrm{C}$ only were used for estimating passive diffusion.

Total, passive, and active uptake of each substrate is shown in Supplemental Figs. 2 and 3, whereas the kinetic constants of active uptake are listed in Table 2. Of note, the $K_{\mathrm{m}}$ values of E3S, CCK-8, and
TCA obtained using hepatocytes were similar to the values determined in HEK293 cells.

The RAFs of OATP1B1, OATP1B3, and NTCP between transfected HEK293 cells and hepatocytes are listed in Table 2. The RAF values indicated that the activity of OATP1B1 in hepatocytes was similar to that in the transfected cells. The activities of OATP1B3 and NTCP in hepatocytes were much lower than in transfected cells, and this was especially evident in lots HUP1001 and HU1651 for OATP1B3. In lot HUM4122D, the RAF values also indicated that in SCHHs compared with suspensions, OATP1B1 activity decreased by 2.4-fold, OATP1B3 activity remained constant, and the NTCP activity increased by 2 -fold. 
TABLE 3

Derivation of passive diffusion clearance and fraction unbound in cells from hepatocyte uptake of pitavastatin at $4{ }^{\circ} \mathrm{C}$

Data in parentheses are coefficient of variation percentages.

\begin{tabular}{lccc}
\hline Hepatocyte Lot and Culture Format & $\mathrm{CL}_{\text {passive }}$ & $\mathrm{f}_{\mathrm{u}, \text { cell }}$ Modeled & $\mathrm{f}_{\mathrm{u}, \text { cell }}$ Steady-State Method \\
\hline & $\mu l /$ min per milligram & & \\
HUM4122D (SCHH) & $23.8(8.1)$ & $0.015(5.5)$ & 0.017 \\
HU1651 (SCHH) & $29.5(21)$ & $0.020(10.3)$ & 0.019 \\
HUM4122D (suspension) & $28.6(6.95)$ & $0.025(4.9)$ & 0.025 \\
HUP1001 (suspension) & $29.5^{a}$ & $\mathrm{NC}^{b}$ & 0.026 \\
\hline
\end{tabular}

$\mathrm{NC}$, not calculated.

${ }^{a}$ Experimentally determined, not modeled.

${ }^{b}$ Not calculated, as $\mathrm{CL}_{\text {passive }}$ in lot HUP1001 was experimentally determined.

\section{Modeling of Hepatocyte Uptake of Pitavastatin at $4^{\circ} \mathrm{C}$ to Derive $\mathbf{C L}_{\text {passive }}$ and $\mathbf{f}_{\mathrm{u} \text {,cell }}$}

Time-dependent uptake of pitavastatin at $4^{\circ} \mathrm{C}$ in hepatocytes was fitted to the two-compartment model (eqs. 6 and 7) to derive $\mathrm{CL}_{\text {passive }}$ and $\mathrm{f}_{\mathrm{u} \text {,cell. }}$. The fits to the uptake data at $4^{\circ} \mathrm{C}$ are shown in Fig. 1, and the derived values of $\mathrm{CL}_{\text {passive }}$ and $\mathrm{f}_{\mathrm{u} \text {,cell }}$ are listed in Table 3 . In addition, $\mathrm{f}_{\mathrm{u}}$, cell estimates from the steady-state method, which is a more commonly employed method of $\mathrm{f}_{\mathrm{u}, \text { cell }}$ determination, are also reported in Table 3 (Shitara et al., 2013). Estimates of $\mathrm{f}_{\mathrm{u}, \mathrm{cell}}$ by the steady-state approach were found to be very similar to those determined by modeling, indicating that the modeling approach is able to generate reliable $f_{u, c e l l}$ estimates, at least for pitavastatin.

\section{Prediction of the Hepatocyte Uptake of Pitavastatin at $37^{\circ} \mathrm{C}$ and Determination of $\mathbf{f}_{\mathbf{t}}$}

Time-dependent uptake of pitavastatin at $37^{\circ} \mathrm{C}$ in hepatocytes was predicted by the two-compartment model (eqs. 6 and 7). For the predictions, all model parameters were incorporated as fixed parameters and none of the parameters were fitted. $\mathrm{CL}_{\text {passive }}$ and $\mathrm{f}_{\mathrm{u}, \text { cell }}$ values derived from modeling of $4^{\circ} \mathrm{C}$ uptake data were used for the $37^{\circ} \mathrm{C}$ predictions, along with the $V_{\max }$ and $K_{\mathrm{m}}$ of each transporter as predicted using the RAF method.

Predictions of time-dependent uptake of pitavastatin in hepatocytes at $37^{\circ} \mathrm{C}$ are shown in Fig. 2. The AFE values were close to unity, indicating that there was no bias for either overprediction or underprediction of pitavastatin disposition in both cells and medium. The AAFE values were $<1.25$, indicating low scatter. The goodness of fit also indicated that RAF values had been correctly estimated and that CLpassive and $f_{u}$, cell derived from $4^{\circ} \mathrm{C}$ incubations are suitable representatives of those parameters at $37^{\circ} \mathrm{C}$ for pitavastatin. Overall, there was good predictive ability in both the suspension and SCHH formats of hepatocytes.

Hepatocyte disposition processes that were modeled for pitavastatin were uptake, bidirectional passive diffusion, basolateral efflux by MRP3, and intracellular binding. As mentioned above, due to the unavailability of a selective MRP3 RAF probe substrate, previously published $K_{\mathrm{m}}(448 \mu \mathrm{M})$ and REF estimates were used for MRP3 (Vildhede et al., 2016). Initial simulations showed that MRP3 had minimal impact on hepatocyte disposition (Supplemental Table 2). Simulations showed that the $V_{\max }$ of MRP3 would need to be considerably higher ( $\geq 10^{4}$-fold) than the currently used $V_{\max }$ to substantially affect cellular accumulation of pitavastatin. From this analysis, it was judged that MRP3 would have minimal impact on intracellular concentrations of pitavastatin. Thus, MRP3 was not considered in the final $f_{t}$ calculations.

For all other processes (transporter and passive diffusion), the $\mathrm{f}_{\mathrm{t}}$ values of pitavastatin were estimated and indicated that the rank order of contributions to hepatocyte uptake of pitavastatin were OATP1B1 > passive diffusion $>$ NTCP $\geq$ OATP1B3 (Table 4). In the suspension and $\mathrm{SCHH}$ formats, the $\mathrm{f}_{\mathrm{t}}$ of OATP1B1 was approximately 0.6 and 0.5 , respectively. In lot HUM4122D, which was the only lot used in both culture formats, there was a $1.3 \times$ decrease in OATP1B1 contribution in SCHHs compared with suspensions, which was less than that indicated by RAF estimates alone $(2.4 \times)$. A significant portion of the total hepatocyte uptake of pitavastatin was by passive diffusion (approximately $30 \%$ in both culture formats). Thus, the actual reduction of OATP1B1 $f_{t}$ in SCHHs compared with suspensions was less pronounced than that indicated by RAF estimates alone. In both culture formats, OATP1B3 constituted $<10 \%$ of total uptake. NTCP contributed $<10 \%$ of the total uptake in suspensions and slightly greater than $10 \%$ of the total uptake in SCHHs.

\section{IVIVCs of Inhibition of Pitavastatin Uptake}

IVIVCs of hepatic uptake inhibition of pitavastatin were estimated for two commonly used OATP inhibitors, rifampicin and cyclosporine. Physiologically based pharmacokinetic (PBPK) modeling of clinical PK data of several OATP substrates has shown that in vitro $K_{\mathrm{i}}$ values are insufficient in recovering clinical PK profiles of these compounds and resulted in significant underpredictions of exposure changes in the presence of inhibitors when used in PBPK models. The general opinion of these studies is that for rifampicin and cyclosporine, in vitro $K_{\mathrm{i}}$ values are lower than the corresponding in vivo $K_{\mathrm{i}}$ values. Subsequently, in these studies, model-optimized $K_{\mathrm{i}}$ values (referred to as in vivo $K_{\mathrm{i}}$ values) led to much improved recovery of PK data (Varma et al., 2012; Jamei et al., 2014; Yoshikado et al., 2016; Duan et al., 2017). Rifampicin and cyclosporine each have in vivo $K_{\mathrm{i}}$ values reported in the literature; therefore, these values were employed for estimating AUCRs of hepatic uptake inhibition in this study. The in vivo $K_{\mathrm{i}}$ values of cyclosporine for inhibition of OATP1B1, OATP1B3, and NTCP are provided in Supplemental Table 3 (Jamei et al., 2014). For rifampicin, an article published by the Food and Drug Administration indicated that the in vivo $K_{\mathrm{i}}$ values of OATP1B1 and OATP1B3 inhibition are at least onetenth of the in vitro values of 0.9 and $0.3 \mu \mathrm{M}$ (Duan et al., 2017). Thus, rifampicin $K_{\mathrm{i}}$ values for OATP1B1 and OATP1B3 were considered to be 0.09 and $0.03 \mu \mathrm{M}$, respectively. For NTCP inhibition by rifampicin, the in vitro $K_{\mathrm{i}}$ value $(138.5 \mu \mathrm{M})$ was used due to a lack of information regarding in vivo $K_{\mathrm{i}}$ values.

The predicted AUCRs of hepatic uptake inhibition of pitavastatin (calculated from eq. 11) are listed in Table 5. In vivo, the AUC of pitavastatin increased by 5.1-6.7-fold in the presence of rifampicin and by 4.6-fold in the presence of cyclosporine (Chen et al., 2013; Prueksaritanont et al., 2014; Kim et al., 2016). The rifampicin studies were conducted in three different populations; in this study, the AUC exposure change observed in the Caucasian population (5.8-fold) was considered to be the benchmark for IVIVCs of hepatic inhibition with rifampicin (Prueksaritanont et al., 2014). It was found that predicted 

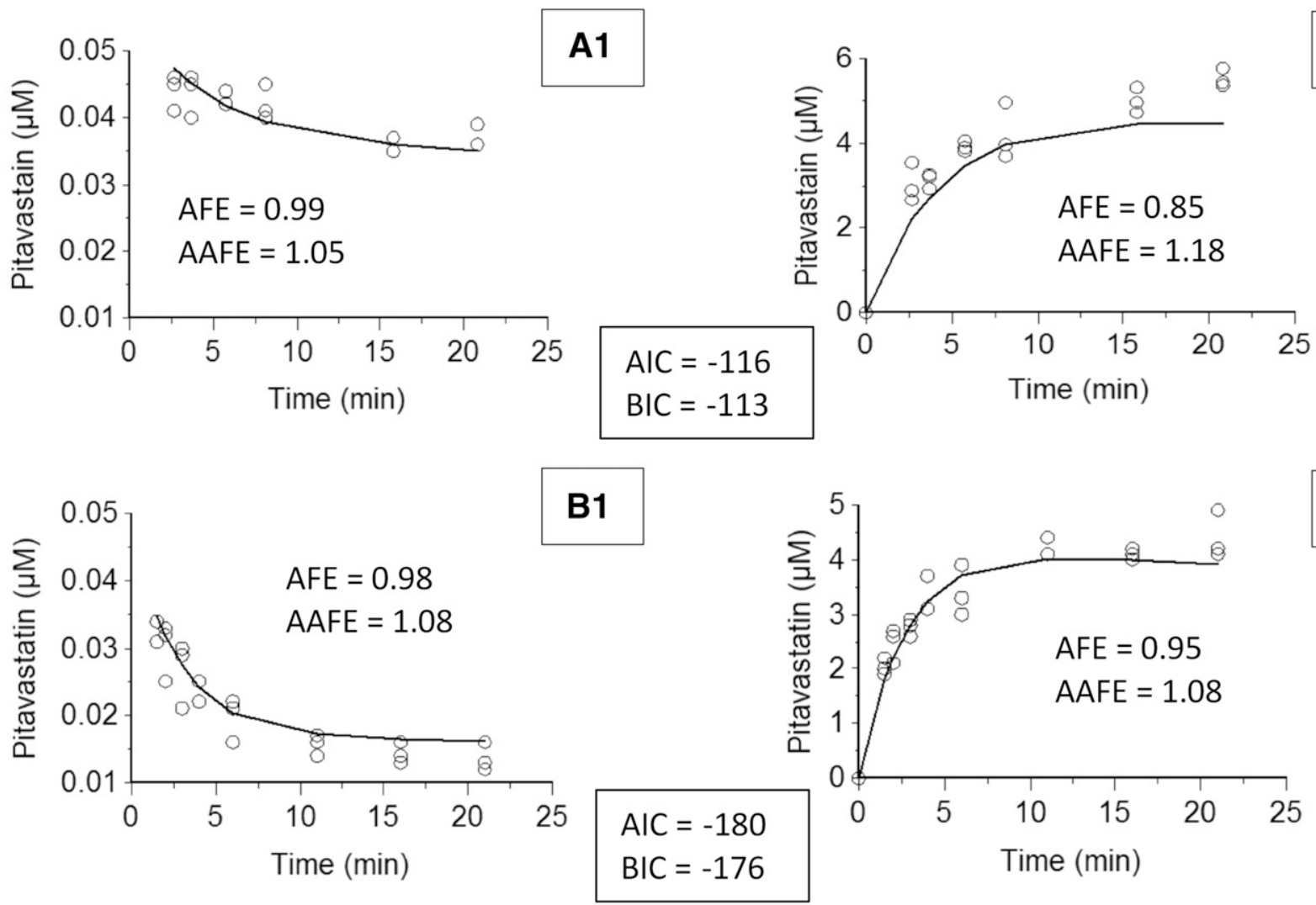

\section{B2}
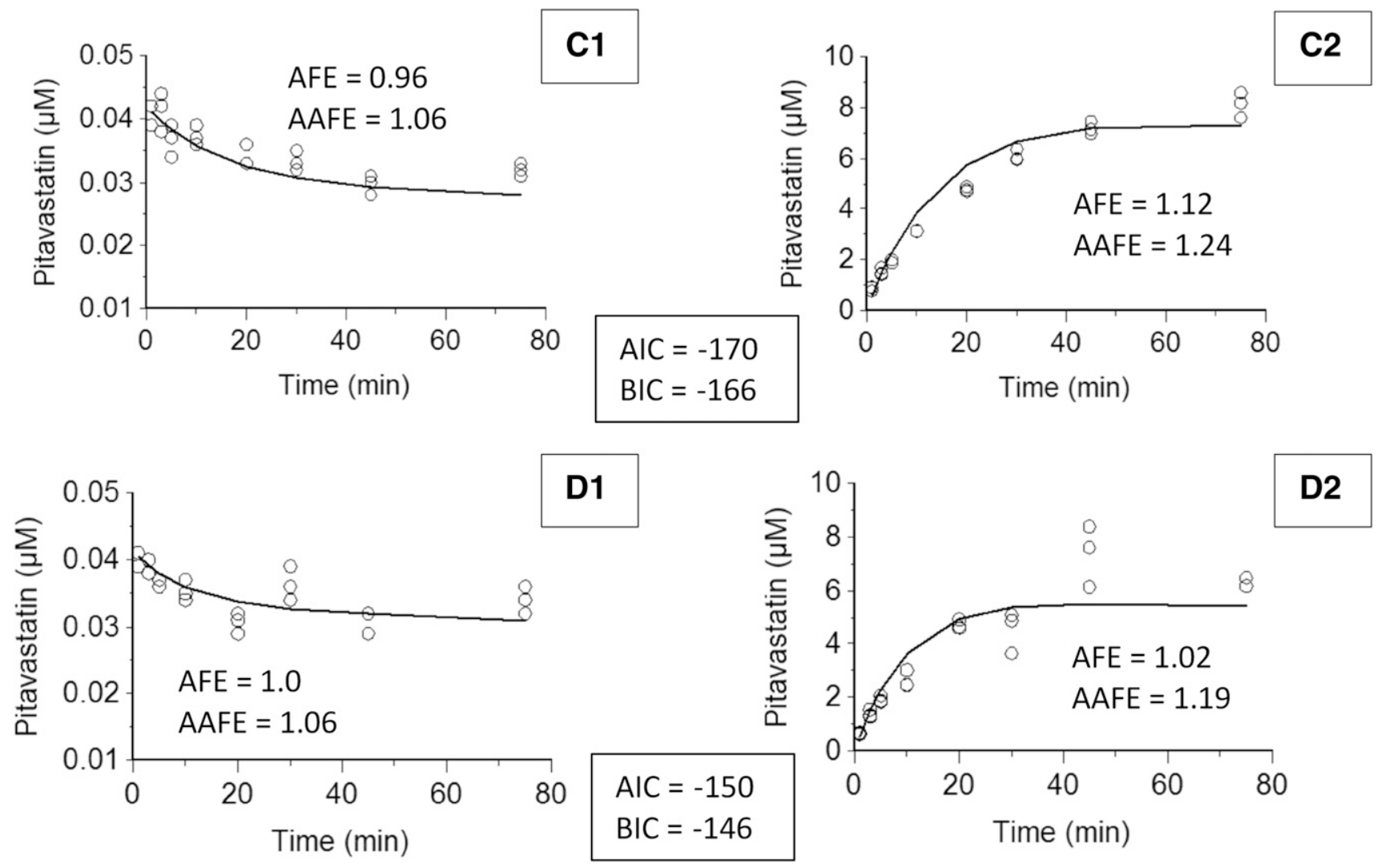

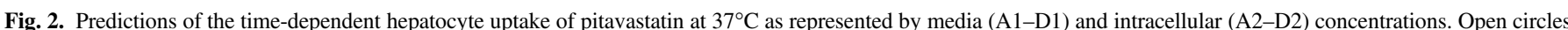

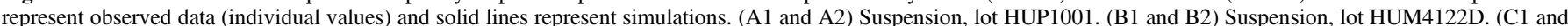
C2) SCHH lot HUM4122D. (D1 and D2) SCHH lot HU1651. 'AIC' is Akaike Information Criteria and 'BIC' is Bayesian Information Criteria.' 
TABLE 4

Contributions of hepatic uptake transporters toward uptake of pitavastatin in hepatocytes

\begin{tabular}{lcc}
\hline Hepatocyte Lot and Culture Format & Transporter & Fraction of Pitavastatin Transported $\left(\mathrm{f}_{\mathrm{t}}\right)$ \\
\hline HUM4122D (SCHH) & OATP1B1 & 0.53 \\
& OATP1B3 & 0.09 \\
& NTCP & 0.09 \\
HU1651 (SCHH) & Passive diffusion & 0.30 \\
& OATP1B1 & 0.48 \\
& OATP1B3 & 0.03 \\
HUP1001 (suspension) & NTCP & 0.17 \\
& Passive diffusion & 0.32 \\
& OATP1B1 & 0.56 \\
HUM4122D (suspension) & OATP1B3 & 0.01 \\
& NTCP & 0.07 \\
& Passive diffusion & 0.37 \\
& OATP1B1 & 0.66 \\
& OATP1B3 & 0.03 \\
& NTCP & 0.02 \\
\hline
\end{tabular}

AUCRs underpredicted observed AUCRs (0.33-0.51-fold for rifampicin and 0.41-0.54-fold for cyclosporine). The underpredictions were not surprising, as it has been shown for many OATP substrates that in vitro hepatic uptake clearance is usually much lower than in vivo hepatic uptake clearance (Jones et al., 2012; Ménochet et al., 2012b; Varma et al., 2012, 2014; Li et al., 2014). This discrepancy is thought to be due to transporter activity differences between in vitro models and liver tissue. For purposes of PBPK modeling or IVIVCs of hepatic uptake, an approach to resolve this discrepancy has been the application of SFs to in vitro uptake clearance. We used a similar approach and applied empirical SFs to the RAF values. Subsequently, hepatocyte uptake of pitavastatin was resimulated and $f_{t}$ values were re-estimated. We observed that SFs of 10-15 resulted in projected AUCRs being within 0.8-1.05-fold of in vivo AUCRs (Table 5).

\section{Discussion}

From a DDI perspective, $f_{t}$ is a valuable parameter in helping refine DDI predictions made through either static equations or PBPK modeling. RAF methods have previously been used for estimating $f_{t}$; however, these estimations have typically described a static process rather than consider the transport of a compound over time. In cases in which RAF approaches have been used in a dynamic manner, the data obtained in transfected cells were not translated to a more holistic model (Mathialagan et al., 2017). The goal of this study was to supplement in vitro RAF data with modeling techniques that allow integration of processes in addition to uptake to predict cellular accumulation in a more holistic model (hepatocytes) and to subsequently determine a more accurate $f_{t}$ value for individual transporters as part of a dynamic process. This should increase the predictive ability of interactions associated with individual transporters and should allow identification of transporter(s) at which DDIs would be most significant.

Pitavastatin was selected as the probe substrate since its metabolic clearance and biliary clearance are low compared with uptake clearance (Watanabe et al., 2010; Varma et al., 2014; Riede et al., 2016; Vildhede et al., 2016). Hepatocyte disposition processes that were modeled for pitavastatin were uptake, bidirectional passive diffusion, basolateral efflux by MRP3, and intracellular binding. Quantification of hepatocyte uptake of pitavastatin by the DRF approach indicated that the primary determinant of pitavastatin hepatocyte uptake was OATP1B1 $\left(\mathrm{f}_{\mathrm{t}}=0.48-\right.$ 0.66 based on total uptake) with minor contributions from OATP1B3 and NTCP $\left(f_{t}=0.01-0.09\right.$ and $0.02-0.13$, respectively). The $f_{t}$ values correlate well with what is known about the in vivo hepatic uptake of pitavastatin (i.e., it is mediated primarily through OATP1B1) (Prueksaritanont et al., 2014). Thus, the DRF approach was able to correctly identify the transporter with the largest uptake contribution. This information may not have been as easily gleaned from studies done in transfected cells alone, where pitavastatin had similar transport efficiencies $\left(V_{\max } / K_{\mathrm{m}}\right)$ for OATP1B1, OATP1B3, and NTCP (Table 1). Of note, MRP3 had minimal impact on pitavastatin hepatocyte

TABLE 5

IVIVC of inhibition of hepatocyte uptake of pitavastatin

\begin{tabular}{lc}
\hline \multicolumn{1}{c}{ AUCR (Observed or Predicted) } & AUCR with Pitavastatin as the Substrate Drug in the Presence of Inhibitor Drugs \\
\cline { 2 - 3 } & Rifampicin \\
\hline Observed in vivo AUCR & $5.8^{a}$ \\
Predicted AUCRs & 2.4 \\
HUM4122D (SCHH) & 1.9 \\
HU1651 (SCHH) & 2.9 \\
HUM4122D (suspension) & 2.2 \\
HUP1001 (suspension) & \\
Simulated AUCRs (the RAF of each transporter was multiplied & \\
by an SF) & $5.6^{b}$ \\
SF $=10$ & 5.8 \\
SF $=15$ & 2.9 \\
\hline
\end{tabular}

${ }^{a}$ The AUCR of pitavastatin in the presence of rifampicin is 5.1-6.7 based on data from three studies conducted across three different populations. The AUCR of 5.8 was observed in the Caucasian population and was considered to be the benchmark in this study (Prueksaritanont et al., 2014).

${ }^{b}$ The AUCR of pitavastatin in the presence of cyclosporine is based on data provided on the Livalo label (can be accessed on the U.S. Food and Drug Administration website at https://www.accessdata.fda.gov/scripts/cder/daf/index.cfm?event=overview.process\&ApplNo=022363). 
accumulation. This result was logical since MRP3 transports pitavastatin with a much lower affinity compared with OATPs and also has a much lower hepatic expression.

In previous studies, static RAF or chemical inhibition approaches have estimated transporter contributions toward hepatocyte uptake of pitavastatin to be $42 \%-95 \%, 1.8 \%-12.3 \%$, and $29 \%$ for OATP1B1, OATP1B3, and NTCP, respectively (Hirano et al., 2004; Bi et al., 2012; Kunze et al., 2014). Some of these studies estimated transporter contributions based on active uptake alone, thus resulting in artificially high $\mathrm{f}_{\mathrm{t}}$ values. More recently, a dynamic REF-based method estimated the $f_{t}$ of OATP1B1 and NTCP to be $57 \%-87 \%$ and $6 \%-22 \%$, respectively (Vildhede et al., 2016). We were interested in evaluating whether an approach similar to that of Vildhede et al., but using translations based on activities instead of expression, is able to simulate hepatocyte disposition. The $\mathrm{f}_{\mathrm{t}}$ values obtained from our DRF approach (48\%-66\%, 1\%-9\%, and 2\%-17\% for OATP1B1, OATP1B3, and NTCP, respectively) indicated that this approach was able to produce results on par with other methods.

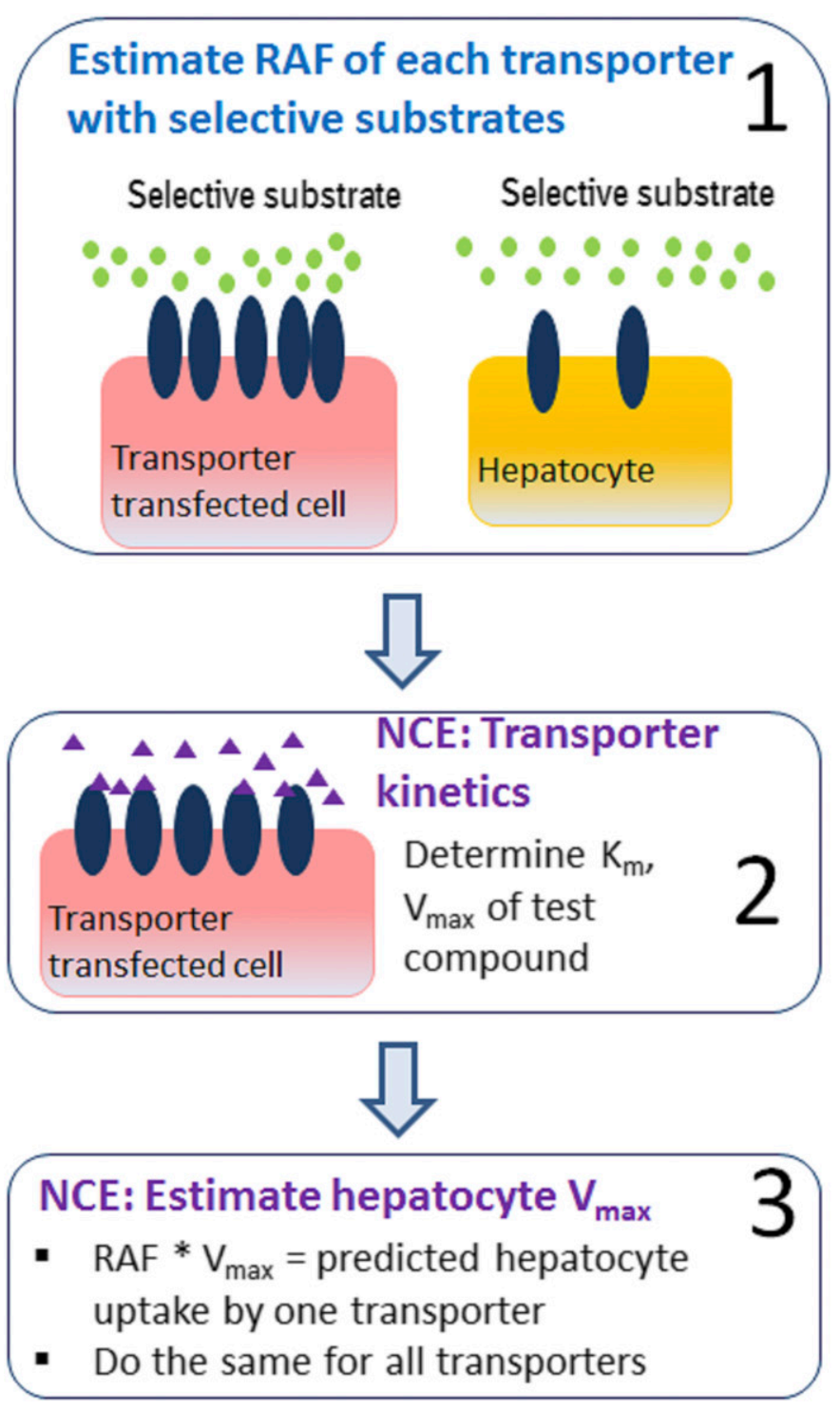

We subsequently employed the $f_{t}$ values to determine the in vitro to in vivo predictive ability of hepatic uptake inhibition of pitavastatin. Incidentally, such pieces of information are of high value to clinical teams. AUC changes of a compound resulting from hepatic uptake inhibition have previously been estimated using either the RowlandMatin equation (Elsby et al., 2012; Shen et al., 2013) or the extended clearance concept (Varma et al., 2014). Here, we used the former approach (eq. 11). Inhibitors considered were rifampicin and cyclosporine due to the wealth of clinical data available for these compounds. We found that AUCR predictions were 0.4-fold of observations in suspensions and 0.5-fold in SCHHs. Back-calculations showed that in order for the predicted AUCRs to be exactly the same as observed AUCRs, active uptake would have to account for $80 \%-88 \%$ of total uptake into hepatocytes. In comparison, the hepatocyte lots used in this study showed $65 \%-70 \%$ active uptake, which led to the $2-2.5 \times$ underpredictions of hepatic uptake inhibition.

The lower-than-optimal percentage of active uptake in hepatocytes may be due to a decrease in transporter activities in hepatocytes

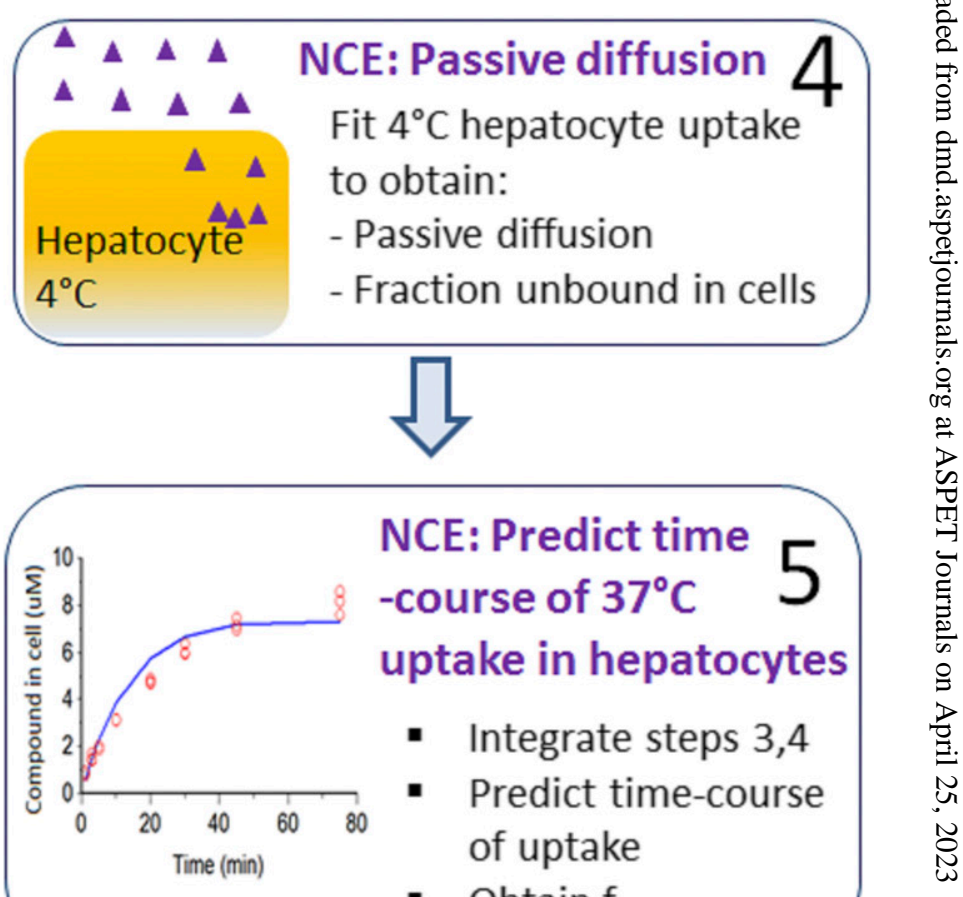

Fig. 3. Road map of predicting in vivo exposure changes of a NCE that is a hepatic uptake transporter substrate by the DRF approach. 
compared with liver tissue. For many OATP1B1/1B3 substrates, in vitro hepatic uptake clearances are seen to be significantly lower than in vivo uptake clearances (Watanabe et al., 2010; Jones et al., 2012; Ménochet et al., 2012b; Varma et al., 2012, 2014; Li et al., 2014). For all of these OATP substrates, application of empirical SFs to in vitro uptake clearances resulted in improved IVIVCs. The SFs are hypothesized to represent activity differences between hepatocytes and liver tissue (Varma et al., 2014). Thus, in our study, after the $2-2.5 \times$ underpredictions of hepatic uptake inhibition, SFs were incorporated into the RAF estimates of each transporter and the effect on IVIVCs was re-evaluated. Simulations suggested that SFs of 10-15 resulted in the desired percentage of active uptake $(80 \%-88 \%)$ and subsequently provided projected AUCRs that were the same as observed AUCRs (Table 5). Thus, while experimentally determined RAF values allowed accurate translation from transfected cells to hepatocytes, SFs were required for bridging the presumable activity differences between hepatocytes and the liver. For accurate IVIVCs of hepatic uptake inhibition of NCEs, we suggest calibration of hepatocytes with prototypical OATP substrates and inhibitors to determine system-specific SFs, which could subsequently be applied toward IVIVCs of hepatic uptake inhibition of the NCE with prototypical OATP inhibitors. However, SFs of OATP substrates exhibit a wide range of values; thus, an SF that works for one particular probe substrate may not be suitable for a new NCE. While this is admittedly a limitation, selection of a probe substrate with similar active and passive uptake properties as the NCE would be a logical approach for determination of system-specific SFs. A road map of the DRF approach is provided in Fig. 3.

Pitavastatin has similar in vitro efficiency $\left(V_{\max } / K_{\mathrm{m}}\right)$ for OATP1B1 and OATP1B3 (Table 1); however the $\mathrm{f}_{\mathrm{t}}$ of the two transporters were remarkably different (OATP1B3, <0.1; OATP1B1, approximately 0.48-0.66). We explored the possible reasons for this difference by researching the relative expression of these transporters. The protein expression ratio of OATP1B3/OATP1B1 is 0.4-0.9:1 in liver tissue and 0.14-0.43:1 in hepatocytes (Badée et al., 2015; Peng et al., 2015; Burt et al., 2016; Prasad et al., 2016). If the in vitro efficiencies of pitavastatin in transfected cells are translated to hepatocyte clearance based on hepatocyte protein expression (assuming that functional activity is directly related to transporter abundance), then hepatocyte clearance of OATP1B3 should be $0.1-0.3 \times$ that of OATP1B1. Our results however indicated that OATP1B3 clearance was $0.02-0.03 \times$ of OATP1B1 clearance. As such, the RAF approach indicated the activity of OATP1B3 compared with OATP1B1 activity to be much less than what would have been expected if transporter expression and activity had a 1:1 correlation. While it is not easy to decipher the reason for this lack of correlation, in most of the protein quantitation studies cited above, protein expression was determined in crude membrane fractions, which presumably will have more protein than that present in plasma membrane fractions alone (Kunze et al., 2014). Further research on plasma membrane quantitation of OATP proteins and on alternative specific substrates of OATP1B3 might shed more light on the extent of correlation between abundance and activities in hepatocytes.

The RAF approach is based on the assumption that probe substrates are selective for the transporters. This is a limitation, since compounds are typically substrates of multiple transporters. However, a way around this limitation may be to utilize probe substrate concentrations that are selective for a particular transporter. For example, E3S has been used as a selective substrate of OATP1B1 for RAF purposes (Hirano et al., 2004; Kunze et al., 2014), but it is a substrate of OATP2B1 and NTCP as well. We found E3S to be a higher-affinity substrate of OATP1B1 $\left(K_{\mathrm{m}}=\right.$ $0.5 \mu \mathrm{M})$ compared with OATP2B1 $\left(K_{\mathrm{m}}=20.2 \mu \mathrm{M}\right)$ and $\operatorname{NTCP}\left(K_{\mathrm{m}}=\right.$ $20.6 \mu \mathrm{M})$. Furthermore, E3S clearances in HEK293-OATP2B1 and HEK293-NTCP cells were only approximately $20 \%-25 \%$ of the clearance in HEK293-OATP1B1 cells (data not shown). Thus, we assumed that at low concentrations $(<5 \mu \mathrm{M})$, E3S can offer selectivity for OATP1B1. In retrospect, this assumption was valid, since there was generally good agreement between observed and predicted hepatocyte uptake of pitavastatin.

In summary, this is the first study to amalgamate in vitro RAF data with modeling techniques that allow integration of multiple processes to estimate $f_{t}$ of hepatic uptake. For pitavastatin, a compound with a minor metabolic component of clearance and where hepatic disposition is uptake limited, the transporter contributions were correctly estimated by this technique. Future studies will evaluate the utility of this approach for $f_{t}$ estimations of compounds for which metabolic and/or biliary clearance is also substantial in relation to uptake clearance. Furthermore, OATP1B1 polymorphisms are known to affect pitavastatin exposure significantly in certain ethnicities. Predicting such changes would be another potential application of the DRF approach.

\section{Acknowledgments}

We thank Dr. Timothy Tracy for careful and constructive review of this manuscript.

\section{Authorship Contributions}

Participated in research design: Mitra, Weinheimer, Taub.

Conducted experiments: Mitra, Weinheimer.

Performed data analysis: Mitra, Weinheimer.

Wrote or contributed to the writing of the manuscript: Mitra, Weinheimer, Michalewicz, Taub.

\section{References}

Badée J, Achour B, Rostami-Hodjegan A, and Galetin A (2015) Meta-analysis of expression of hepatic organic anion-transporting polypeptide (OATP) transporters in cellular systems relative to human liver tissue. Drug Metab Dispos 43:424-432.

Bi YA, Kimoto E, Sevidal S, Jones HM, Barton HA, Kempshall S, Whalen KM, Zhang H, Ji C, Fenner KS, et al. (2012) In vitro evaluation of hepatic transporter-mediated clinical drug-drug interactions: hepatocyte model optimization and retrospective investigation. Drug Metab Dispos 40:1085-1092.

Bi YA, Qiu X, Rotter CJ, Kimoto E, Piotrowski M, Varma MV, Ei-Kattan AF, and Lai Y (2013) Quantitative assessment of the contribution of sodium-dependent taurocholate co-transporting polypeptide (NTCP) to the hepatic uptake of rosuvastatin, pitavastatin and fluvastatin. Biopharm Drug Dispos 34:452-461.

Burt HJ, Riedmaier AE, Harwood MD, Crewe HK, Gill KL, and Neuhoff S (2016) Abundance of hepatic transporters in Caucasians: a meta-analysis. Drug Metab Dispos 44:1550-1561.

Chapy H, Klieber S, Brun P, Gerbal-Chaloin S, Boulenc X, and Nicolas O (2015) PBPK modeling of irbesartan: incorporation of hepatic uptake. Biopharm Drug Dispos 36:491-506.

Chen Y, Zhang W, Huang WH, Tan ZR, Wang YC, Huang X, and Zhou HH (2013) Effect of a single-dose rifampin on the pharmacokinetics of pitavastatin in healthy volunteers. Eur J Clin Pharmacol 69:1933-1938.

De Bruyn T, Sempels W, Snoeys J, Holmstock N, Chatterjee S, Stieger B, Augustijns P, Hofkens J, Mizuno H, and Annaert P (2014) Confocal imaging with a fluorescent bile acid analogue closely mimicking hepatic taurocholate disposition. J Pharm Sci 103:1872-1881.

DeGorter MK, Ho RH, Leake BF, Tirona RG, and Kim RB (2012) Interaction of three regiospecific amino acid residues is required for OATP1B1 gain of OATP1B3 substrate specificity. Mol Pharm 9:986-995.

Duan P, Zhao P, and Zhang L (2017) Physiologically based pharmacokinetic (PBPK) modeling of pitavastatin and atorvastatin to predict drug-drug interactions (DDIs). Eur J Drug Metab Pharmacokinet 42:689-705.

Elsby R, Hilgendorf C, and Fenner K (2012) Understanding the critical disposition pathways of statins to assess drug-drug interaction risk during drug development: it's not just about OATP1B1. Clin Pharmacol Ther 92:584-598.

Gozalpour E, Greupink R, Wortelboer HM, Bilos A, Schreurs M, Russel FG, and Koenderink JB (2014) Interaction of digitalis-like compounds with liver uptake transporters NTCP, OATP1B1, and OATP1B3. Mol Pharm 11:1844-1855.

Hirano M, Maeda K, Shitara Y, and Sugiyama Y (2004) Contribution of OATP2 (OATP1B1) and OATP8 (OATP1B3) to the hepatic uptake of pitavastatin in humans. J Pharmacol Exp Ther 311: $139-146$.

Izumi S, Nozaki Y, Maeda K, Komori T, Takenaka O, Kusuhara H, and Sugiyama Y (2015) Investigation of the impact of substrate selection on in vitro organic anion transporting polypeptide 1B1 inhibition profiles for the prediction of drug-drug interactions. Drug Metab Dispos 43:235-247.

Jamei M, Bajot F, Neuhoff S, Barter Z, Yang J, Rostami-Hodjegan A, and Rowland-Yeo K (2014) A mechanistic framework for in vitro-in vivo extrapolation of liver membrane transporters: prediction of drug-drug interaction between rosuvastatin and cyclosporine. Clin Pharmacokinet 53:73-87.

Jigorel E and Houston JB (2012) Utility of drug depletion-time profiles in isolated hepatocytes for accessing hepatic uptake clearance: identifying rate-limiting steps and role of passive processes Drug Metab Dispos 40:1596-1602. 
Jones HM, Barton HA, Lai Y, Bi YA, Kimoto E, Kempshall S, Tate SC, El-Kattan A, Houston JB, Galetin A, et al. (2012) Mechanistic pharmacokinetic modeling for the prediction of transportermediated disposition in humans from sandwich culture human hepatocyte data. Drug Metab Dispos 40:1007-1017.

Kim SJ, Yoshikado T, Ieiri I, Maeda K, Kimura M, Irie S, Kusuhara H, and Sugiyama Y (2016) Clarification of the mechanism of clopidogrel-mediated drug-drug interaction in a clinical cassette small-dose study and its prediction based on in vitro information. Drug Metab Dispos 44 $1622-1632$.

Kimoto E, Yoshida K, Balogh LM, Bi YA, Maeda K, El-Kattan A, Sugiyama Y, and Lai Y (2012) Characterization of organic anion transporting polypeptide (OATP) expression and its functional contribution to the uptake of substrates in human hepatocytes. Mol Pharm 9:3535-3542.

Kunze A, Huwyler J, Camenisch G, and Poller B (2014) Prediction of organic anion-transporting polypeptide 1B1- and 1B3-mediated hepatic uptake of statins based on transporter protein expression and activity data. Drug Metab Dispos 42:1514-1521.

Leonhardt M, Keiser M, Oswald S, Kühn J, Jia J, Grube M, Kroemer HK, Siegmund W, and Weitschies W (2010) Hepatic uptake of the magnetic resonance imaging contrast agent Gd-EOB-DTPA: role of human organic anion transporters. Drug Metab Dispos 38:1024-1028

Li R, Barton HA, Yates PD, Ghosh A, Wolford AC, Riccardi KA, and Maurer TS (2014) A "middle-out" approach to human pharmacokinetic predictions for OATP substrates using physiologically-based pharmacokinetic modeling. J Pharmacokinet Pharmacodyn 41:197-209.

Marada VV, Flörl S, Kühne A, Burckhardt G, and Hagos Y (2015) Interaction of human organic anion transporter polypeptides 1B1 and 1B3 with antineoplastic compounds. Eur J Med Chem 92:723-731.

Mathialagan S, Piotrowski MA, Tess DA, Feng B, Litchfield J, and Varma MV (2017) Quantitative prediction of human renal clearance and drug-drug interactions of organic anion transporter substrates using in vitro transport data: a relative activity factor approach. Drug Metab Dispos 45:409-417.

Ménochet K, Kenworthy KE, Houston JB, and Galetin A (2012a) Simultaneous assessment of uptake and metabolism in rat hepatocytes: a comprehensive mechanistic model. J Pharmacol Exp Ther 341:2-15.

Ménochet K, Kenworthy KE, Houston JB, and Galetin A (2012b) Use of mechanistic modeling to assess interindividual variability and interspecies differences in active uptake in human and rat hepatocytes. Drug Metab Dispos 40:1744-1756.

Peng KW, Bacon J, Zheng M, Guo Y, and Wang MZ (2015) Ethnic variability in the expression of hepatic drug transporters: absolute quantification by an optimized targeted quantitative proteomic approach. Drug Metab Dispos 43:1045-1055.

Pfeifer ND, Harris KB, Yan GZ, and Brouwer KL (2013) Determination of intracellular unbound concentrations and subcellular localization of drugs in rat sandwich-cultured hepatocytes compared with liver tissue. Drug Metab Dispos 41:1949-1956.

Prasad B, Gaedigk A, Vrana M, Gaedigk R, Leeder JS, Salphati L, Chu X, Xiao G, Hop C, Evers R, et al. (2016) Ontogeny of hepatic drug transporters as quantified by LC-MS/MS proteomics. Clin Pharmacol Ther 100:362-370.

Prueksaritanont T, Chu X, Evers R, Klopfer SO, Caro L, Kothare PA, Dempsey C, Rasmussen S, Houle R, Chan G, et al. (2014) Pitavastatin is a more sensitive and selective organic aniontransporting polypeptide 1B clinical probe than rosuvastatin. Br J Clin Pharmacol 78:587-598.

Ramsden D, Tweedie DJ, Chan TS, Taub ME, and Li Y (2014) Bridging in vitro and in vivo metabolism and transport of faldaprevir in human using a novel cocultured human hepatocyte system, HepatoPac. Drug Metab Dispos 42:394-406.

Riede J, Poller B, Umehara K, Huwyler J, and Camenisch G (2016) New IVIVE method for the prediction of total human clearance and relative elimination pathway contributions from in vitro hepatocyte and microsome data. Eur J Pharm Sci 86:96-102.
Schwarz UI, Meyer zu Schwabedissen HE, Tirona RG, Suzuki A, Leake BF, Mokrab Y, Mizuguchi K. Ho RH, and Kim RB (2011) Identification of novel functional organic aniontransporting polypeptide 1B3 polymorphisms and assessment of substrate specificity. Pharmacogenet Genomics 21:103-114

Sharma P, Butters CJ, Smith V, Elsby R, and Surry D (2012) Prediction of the in vivo OATP1B1mediated drug-drug interaction potential of an investigational drug against a range of statins. Eur J Pharm Sci 47:244-255.

Shen H, Yang Z, Mintier G, Han YH, Chen C, Balimane P, Jemal M, Zhao W, Zhang R, Kallipatti $\mathrm{S}$, et al. (2013) Cynomolgus monkey as a potential model to assess drug interactions involving hepatic organic anion transporting polypeptides: in vitro, in vivo, and in vitro-to-in vivo extrapolation. J Pharmacol Exp Ther 344:673-685.

Shitara Y, Itoh T, Sato H, Li AP, and Sugiyama Y (2003) Inhibition of transporter-mediated hepatic uptake as a mechanism for drug-drug interaction between cerivastatin and cyclosporin A. $J$ Pharmacol Exp Ther 304:610-616.

Shitara Y, Maeda K, Ikejiri K, Yoshida K, Horie T, and Sugiyama Y (2013) Clinical significance of organic anion transporting polypeptides (OATPs) in drug disposition: their roles in hepatic clearance and intestinal absorption. Biopharm Drug Dispos 34:45-78.

Soars MG, Barton P, Ismair M, Jupp R, and Riley RJ (2012) The development, characterization, and application of an OATP1B1 inhibition assay in drug discovery. Drug Metab Dispos 40 1641-1648.

Stoscheck CM (1990) Quantitation of protein. Methods Enzymol 182:50-68.

Taub ME, Mease K, Sane RS, Watson CA, Chen L, Ellens H, Hirakawa B, Reyner EL, Jani M, and Lee CA (2011) Digoxin is not a substrate for organic anion-transporting polypeptide transporters OATP1A2, OATP1B1, OATP1B3, and OATP2B1 but is a substrate for a sodiumdependent transporter expressed in HEK293 cells. Drug Metab Dispos 39:2093-2102.

Varma MV, Bi YA, Kimoto E, and Lin J (2014) Quantitative prediction of transporter- and enzyme-mediated clinical drug-drug interactions of organic anion-transporting polypeptide 1B1 substrates using a mechanistic net-effect model. J Pharmacol Exp Ther 351:214-223.

Varma MV, Lai Y, Feng B, Litchfield J, Goosen TC, and Bergman A (2012) Physiologically based modeling of pravastatin transporter-mediated hepatobiliary disposition and drug-drug interactions. Pharm Res 29:2860-2873.

Vildhede A, Mateus A, Khan EK, Lai Y, Karlgren M, Artursson P, and Kjellsson MC (2016) Mechanistic modeling of pitavastatin disposition in sandwich-cultured human hepatocytes: a proteomics-informed bottom-up approach. Drug Metab Dispos 44:505-516.

Watanabe T, Kusuhara H, Maeda K, Kanamaru H, Saito Y, Hu Z, and Sugiyama Y (2010) Investigation of the rate-determining process in the hepatic elimination of HMG-CoA reductase inhibitors in rats and humans. Drug Metab Dispos 38:215-222.

Williamson B, Soars AC, Owen A, White P, Riley RJ, and Soars MG (2013) Dissecting the relative contribution of OATP1B1-mediated uptake of xenobiotics into human hepatocytes using siRNA. Xenobiotica 43:920-931.

Yoshikado T, Yoshida K, Kotani N, Nakada T, Asaumi R, Toshimoto K, Maeda K, Kusuhara H, and Sugiyama Y (2016) Quantitative analyses of hepatic OATP-mediated interactions between statins and inhibitors using PBPK modeling with a parameter optimization method. Clin Pharmacol Ther 100:513-523.

Address correspondence to: Pallabi Mitra, Drug Metabolism and Pharmacokinetics Department, Boehringer Ingelheim Pharmaceuticals Inc., 900 Ridgebury Road, Ridgefield, CT 06877. E-mail: pallabi.mitra@boehringer-ingelheim.com 